\title{
Nicaragua en los cuentos de Rubén Darío
}

\author{
Sylma GARCÍA GONZÁLEZ \\ Universidad de Puerto Rico
}

\begin{abstract}
RESUMEN
Una breve mirada al acervo crítico sobre los cuentos de Rubén Darío es suficiente para concluir que esta faceta de su obra literaria ha despertado un interés menor en la crítica internacional que su producción poética. Además, aunque inestimable para la historia general del cuento español e hispanoamericano, su narrativa se considera en una posición secundaria frente a la genialidad estético-literaria de su poesía. A pesar de que resulta imposible negar las influencias francesas y españolas que los críticos han señalado tan acertadamente, sería interesante estudiar el posible diálogo entre Darío y su tradición cultural centroamericana, especialmente nicaragüense. Por otra parte, cabe destacar que quienes no toman en cuenta la importancia de Centroamérica y de Nicaragua en dichos cuentos son, por lo general, críticos internacionales, ya que los críticos nicaragüenses han percibido claramente en estas obras una innegable influencia nacional, aunque de resonancias universales.
\end{abstract}

Palabras clave: cuentos, tradición, Nicaragua, cultura, identidad.

\section{Nicaragua in Rubén Darío's Short Stories}

\begin{abstract}
A brief view of the critic treasures about the stories of Ruben Dario is sufficient to conclude that this phase of his literary job woke up a minor interest on his poetic production in the international criticism. In addition, even if is inestimable for history in general of the Spanish and Latin-American stories, his narrative is considerate on a post secondary position in front of a genuine esthetic literary on his poetry. Even if this result is impossible to deny, the French and Spanish influences that the critics point was accurately, it will be interesting to study the possible dialog between Dario and his Central American cultural tradition, especially Nicaraguans. In other part, we must emphasize that the ones that will not consider the importance of the Central American and Nicaragua on those stories are in general international critics while Nicaraguan critics perceive clearly in this masterpiece an undeniable national influence while of universal resonance.
\end{abstract}

Keywords: short stories, tradition, Nicaragua, culture, identity.

A Ramón Luis Acevedo 
Dice el poeta Pablo Antonio Cuadra, en su libro El nicaragüense: "[...] descubrí que Rubén decía a Nicaragua. Que era su palabra. La palabra del nicaragüense" (1969: 82). Esta sencilla, a la vez que cargadísima afirmación, no hace sino confirmar aquello que se puede intuir tras la lectura de los Cuentos completos de Rubén Darío. Sin embargo, tras una seria revisión de la crítica literaria acerca de la cuentística rubendariana, encontramos que, en primer lugar, esta faceta de su obra ha despertado un interés menor que su producción poética en la crítica internacional y que, aunque inestimable para la historia general del cuento español e hispanoamericano, su narrativa se considera en una posición secundaria frente a la genialidad estéticoliteraria de su poesía. Admite el crítico argentino Raimundo Lida, al final de su ensayo "Los cuentos de Rubén Darío", incluido en la colección de cuentos del poeta: "Poco significan, en cantidad los ochenta cuentos de Rubén dentro de la mole total de su prosa, ni en calidad pueden corresponderles, junto a sus poemas, sino una gloria modesta y marginal" (Darío 1950: 199).

Ya desde la primera página del ensayo, el estudioso argentino apuesta a la literatura francesa como la mayor influencia de Darío, "[...]decisiva, la seducción del cuento francés, ceñido y brillante" (Darío 1950: 200), luego su tradición colonial española y a los clásicos universales, prácticamente ignorando cualquier posible influencia o relación con la tradición cultural centroamericana y, mucho menos, con la nicaragüense. Resulta a todas luces imposible negar las evidentísimas influencias destacadas por Lida; mas sería interesante enfilar los cañones hacia el posible diálogo entre Darío y su tradición cultural centroamericana, especialmente nicaragüense, relación que estudiosos como Carlos Martín, en América en Rubén Dario (1972), han encontrado en su poesía. Por otra parte, cabe destacar que quienes no toman en cuenta la importancia de Centroamérica y de Nicaragua en dichos cuentos son, por lo general, críticos internacionales, mientras que críticos nicaragüenses como Jorge Eduardo Arellano (1977) y el poeta Ernesto Cardenal (1949) perciben en esta obra una innegable influencia nacional, aunque de resonancias universales.

A pesar de que la mayor parte de su obra literaria fue producida fuera de Centroamérica y, por supuesto, de Nicaragua, cabe mencionar algunos cuentos de los primeros años de su vida de escritor que, si no son los de mayor esplendor, son un reflejo de la enorme vocación y el maravilloso talento de Darío, como lo demuestra el estudio Rubén Dario, criollo; o, Raíz y médula de su creación poética (1945) de Diego Manuel Sequeira. Entre los cuentos de este periodo se encuentran "A las orillas del Rhin" (1885), "Las albóndigas del coronel" (1885) y "Mis primeros versos" (1886), escritos en Nicaragua; "La muerte de la emperatriz de China" (1889), escrito en El Salvador; "El Dios bueno" (1890), "Betún y sangre" (1890), "La novela de uno de tantos" (1890), escritos en Guatemala; "La muerte de Salomé" (1891), "El árbol del rey David" (1891), "Fugitiva" (1892), "Rojo" (1892), "Historia de un sobretodo" (1892), "Las pérdidas de Juan Bueno" (1892), “Por qué?” (1892), "La resurrección de la rosa" (1892) y "Un sermón" (1892), escritos en Costa Rica. Estos dieciséis cuentos, aunque no representan la culminación de Darío en este género literario, son una variada serie de temas y de técnicas narrativas que van desde el tema medieval de su primer tanteo hasta los relatos de corte autobiográfico. 
Entre estos cuentos centroamericanos, cabe destacar, algunos que presentan ciertos rasgos que son característicos de los países centroamericanos. En primer lugar, el autor utiliza a menudo algunos vocablos y expresiones propias de la región, por ejemplo, en "Betún y sangre", aparecen algunos regionalismos guatemaltecos; lo que indica no solo la familiaridad de Darío con estos, sino también su uso deliberado con el objetivo de darle a la narración un evidente sabor local. La abuela del protagonista habla de canche para referirse a un rubio, mientras el capitán Andrés emplea deliberadamente ciertos remedos del lenguaje infantil centroamericano: “¿Por qué no levanta a niña bonita? ¡Vamo a darle uno azote!” (Darío 1950: 140). Por otra parte, el escritor hace gala de sus conocimientos acerca de la historia y la cultura de Guatemala, al referirse a la ciudad capital como Antigua, nombre de la segunda Guatemala, fundada en 1542, destruida por los terremotos en 1773, y al aludir a chojín, un plato regional guatemalteco. Por otro lado, en su cuento "La novela de uno de tantos", se encuentra el vocablo centroamericano chivo para referirse al juego de dados; y en su cuento "Morbo et umbra2" aparece la expresión el vuelto como se dice en Nicaragua y, en general, en América, sobre la forma española la vuelta.

Muchos críticos argumentan que los temas nicaragüenses como las costumbres, la historia y el paisaje, están parcial o totalmente ausentes de los cuentos de Darío, absorbidos por los temas europeos. Jaime Torres Bodet afirma en su libro Rubén Dario:

Brilla poco, en sus paisajes del trópico, el sol ardiente de Centroamérica. Sus primaveras y sus otoños son europeos. Y sus colores predilectos (el azul del Mediterráneo, el rosa y el verde de las campiñas de Francia) no evocan siempre el clima de Nicaragua. (1966: 129)

Por otro lado, el escritor nicaragüense Julio Ycaza Tigerino argumenta que toda la literatura narrativa y descriptiva rubendariana se identifica con la naturaleza de su país natal, a pesar de haber sido escrita en Europa, América u otros lugares del mundo (1967: 285). Me parece que esta posible identificación con su tierra natal se encuentra ricamente adornada con el tono musical, la hermosura y la delicadeza de las imágenes y el evidente refinamiento cultural que caracteriza la obra literaria de Darío, pero permanece en esencia allí. El propio poeta declaraba la innegable e insustituible presencia de su tierra en su vida y, por ende, en su literatura:

Yo sé lo que debo a la tierra de mi infancia y a la ciudad de mi primera juventud; no creáis que en mis agitaciones de París, que en mis noches de Madrid, o en mis tardes de Roma, que en mis crepúsculos de Palma de Mallorca, no he tenido pensares como estos: un sonar de viejas campanas de nuestra catedral [...]. (Darío 1968: 1027)

En el antes mencionado libro, El nicaragüense, Cuadra expone una serie de características que culturalmente se han considerado muy relacionadas con el modo de ser y de ver la vida de sus compatriotas. Algunos de estos rasgos "propiamente nicaragüenses" pueden identificarse en los cuentos de Darío, escritos dentro y fuera 
de su país. En primer lugar, llama muchísimo la atención los planteamientos hechos por el autor acerca de la naturaleza dual del nicaragüense, ejemplificada por unas estatuas de piedra muy antiguas que representan el tema del ser humano con un animal adherido a su espalda:

Esas esculturas monumentales me hablaban de una concepción mítica y misteriosa del 'doble yo' o alter ego vital que significó, seguramente, todo un movimiento religioso o mágico animista, forjado por una cultura muy antigua. [...] ¿Sería el nicaragüense un hombre dividido por la duda?... ¿Estarían siempre -empujados por ese destino- afrontando disyuntivas desgarradoras? ¿O es el nicaragüense la fusión de los antagonismos, la unificación de los contrastes? (Cuadra 1969: 10-2)

Cuadra asegura que Darío plasmó en su literatura, especialmente en su poesía, la esencia dual que caracteriza a su pueblo, comenzando por los conocidísimos versos de su poema "Constelaciones”: “¿Pero qué voy a hacer, si estoy atado al potro / en que, ganando el premio, siempre quiero ser otro, / y en que, dos en mí mismo, triunfa uno de los dos?". Además, Cuadra se autoriza con los comentarios de algunos críticos de la obra rubendariana como Moshe Lazar (quien habla de "la proyección poética de una dualidad"), Pedro Salinas, Octavio Paz y el propio Darío: "siempre quiero ser otro" (Cuadra 1969: 16). Parece que, a diferencia del tratamiento directo de esta "dualidad nicaragüense" en algunos de sus poemas, en los cuentos este aspecto es menos evidente y, posiblemente, inconsciente. Se puede apreciar la común aparición de seres duales o de naturaleza múltiple, como son los sátiros y los centauros, que aparecen en los cuentos: "El sátiro sordo" y "Palimpsesto (II)". Si bien es cierto que el uso de estas figuras mitológicas como personajes de sus cuentos son producto de la amplia cultura clásica del poeta y de sus influencias literarias europeas, es posible que estos seres fabulosos sean, a nivel muy profundo, una especie de reminiscencia de aquellas estatuas antiguas de los indígenas de la zona nicaragüense que Cuadra considera, a su vez, símbolos de la naturaleza dual de su cultura y de su pueblo. En el cuento "Palimpsesto (II)", el autor pone en boca de un sabio anciano unas palabras que, contempladas a través de esta nueva luz, bien podrían interpretarse como una reflexión acerca de estas extrañas estatuas que tanto han inquietado a los nicaragüense por su posible relación con su propia identidad: "En verdad, hermano, que ambos tendrán su premio; la mitad de ellos pertenece a las bestias, de las cuales cuida Dios solo; la otra mitad es del hombre, y la justicia eterna la premia o la castiga" (Darío 1950: 290). Por otro lado, Ernesto Cardenal percibe al poeta como un navegante en busca de nuevos puertos, anhelos de aventura que van a tono con la esencia del ser nicaragüense: "La misma anatomía geográfica de la tierra le da una configuración de puente, de tierra de paso, de tránsito, no de permanencia, y toda nuestra historia es una historia de viajes y aventuras de mar" (1949: 11-2). José Coronel Urtrecho va más allá al enfatizar la universalidad del pueblo nicaragüense, "La propensión o inclinación a la universalidad ha sido más que todo un elemento del carácter, una característica vital, por no decir biológica, del hombre de Nicaragua", hasta llegar a afirmar una verdad ineludible: "La más alta manifestación de la universalidad 
nicaragüense es, por supuesto, Rubén Darío" (1966: 2). Todos sabemos que en muchos de los cuentos de Darío, así como en muchos de sus poemas, es evidente el deseo incontenible de viajar y conocer otras culturas y civilizaciones. Por este motivo, pasan ante nuestros ojos hermosas descripciones paisajistas de Chile, las costas de África, París.

Otra característica que Pablo Antonio Cuadra señala como muy propia de la idiosincrasia nicaragüense es su profundo sentido del humor:

[...] Lo cierto es que el tipo nicaragüense llena de risa, empaca en risa, casi toda su actividad vital. Hasta su tragedia, cuando la tiene, la hace girar sutilmente hacia el terreno burlesco. En nuestro folklore, las consejas, cuentos y fábulas más populares son una expresión didáctica de esta tesis. La 'burla' es un elemento educador creado por nuestra literatura popular, el arma para dar en el blanco de la moraleja. (Cuadra 1969: 46)

Sin duda, Rubén Darío poseía una fuerte vena "burlesca" de profunda raíz nacional. Muchos de sus cuentos emplean elementos jocosos; algunos de ellos sorprenden con finales verdaderamente graciosos, que terminan llevando al lector a dar una sincera carcajada. En el brevísimo cuento "El nacimiento de la col", se pretende explicar el origen de dicho vegetal como la transformación de una rosa que deseaba ser útil, además de bella. Esta narración, a través del recurso de un humor chispeante y sano, lleva el mensaje de que el artista debe cuidar de que la belleza no se contamine con el afán utilitario. Otro cuento que resulta graciosísimo, aunque podría parecer un poco blasfemo es "Las pérdidas de Juan Bueno", en el que San José pierde la paciencia con la mojigatería de este pobre Juan Bueno, dándole un golpe con su florido bastón en las orejas y enviándolo a buscar a su insoportable mujer al infierno.

Por otra parte, Darío conoció muy bien la tradición popular de su patria nicaragüense, como lo demuestra su cuento "Hebraico", que no es otra cosa que una alusión a las aventuras del famoso Tío Conejo (Cuadra 1969: 47), ingenioso y burlador, quien podríamos decir que representa la vena "burlesca" que caracteriza a dicha cultura. En "Hebraico", el autor recurre nuevamente a una especie de reescritura de ciertos pasajes bíblicos para explicar que no esté prohibido comer carne de conejo por los padres del desierto. Sin embargo, a diferencia de los cuentos populares de Nicaragua, el conejo de esta historia no sale muy bien parado, a pesar de haber puesto todo su ingenio para salvarse de ser comido, ya que por su imperdonable imprudencia se traiciona a sí mismo y a toda su raza, al propiciar, sin quererlo, que Aarón y Moisés probaran la carne de conejo y les gustara.

Tras estas disquisiciones acerca de la esencia del carácter nicaragüense, se entrará de lleno en el análisis de los cuentos que ejemplifican la antes mencionada presencia de su patria en Darío. Su primer cuento, titulado "A las orillas del Rhin", a pesar de haber sido escrito en Nicaragua posee pocos puntos de contacto con esta presencia por tratarse de un tema medieval. Sin embargo, parece que el autor, quien utiliza por primera vez el recurso de la dedicatoria intercalada para darle mayor 
intimidad al relato, lo hace también con el propósito de mantener un hilillo que lo una a su entorno vital, ya que le dedica esta narración a Adela Elizondo, joven nicaragüense e hija de don Joaquín Elizondo, en ese tiempo, Ministro de la Guerra: "Estáme atenta, Adela, tú que eres tan amiga de los cuentos preciosos; sobre todo de aquellos en que resplandece el amor y refrescan el espíritu con la dulzura de sus encantos"(Darío 1950: 3).

En su cuento "Las albóndigas del Coronel", Darío sigue de cerca las famosas Tradiciones peruanas (1883) de Ricardo Palma, al identificar, desde el mismo título, su narración breve como una "Tradición nicaragüense". En este segundo cuento, se observa el interés del escritor por resaltar las tradiciones y el folclor de su país a través de un humor alegre y chispeante, una de las características que Cuadra identifica con la forma de ser nicaragüense. El autor comienza la historia explicándole al lector quién era el Coronel Joaquín Arrechavala: "Allá por aquellos años, en que ya estaba para concluir el régimen colonial, era gobernador de León el famoso Coronel Arrechavala, cuyo nombre no hay vieja que no lo sepa, y cuyas riquezas son proverbiales; que cuentan que tenía adobes de oro" (Darío 1950: 10). El Coronel fue un personaje histórico que ocupó interinamente la Gobernación de la Provincia de Nicaragua (1813-1819). En una nota al pie de este cuento, Raimundo Lida dice que, "Su figura se ha vuelto legendaria en ese país: aparece, siempre a caballo, como protagonista de anécdotas amorosas y cuentos de aparecidos" (Darío 1950: 10). Además, para que no quede duda de la existencia de este personaje, Darío indica que, "Aún pueden mis lectores conocer los restos de sus posesiones pasando por la hacienda 'Los Arcos', cercana a León” (Darío 1950: 10).

Darío añade una nueva faceta a este sobrio personaje, ya que el cuento narra una situación jocosa entre dicho Coronel y doña María, una viuda de la ciudad, quien solía preparar ricos platillos para él. Según la historia, el Coronel era muy amante de las albóndigas y doña María, para satisfacerlo, decide prepararlas y enviárselas con uno de sus hijos en su mejor sopera. Al otro día, durante su visita diaria a casa de la dama, Arrechavala le dice entre risas que olvidó incluir las albóndigas en la sopera. Doña María envía a llamar a su hijo y este, muy asustado, le confiesa que se le derramaron en la calle y solo pudo conservar el caldo. El Coronel salva la situación restándole importancia y hasta le regala una moneda al niño, no sin antes pedirle a la viuda que le envíe más albóndigas al otro día: "El generoso militar tomó la calle, y fuése, y tuvo para reír por mucho tiempo. Tanto, que poco antes de morir refería el cuento entre carcajada y carcajada. Y a fe que desde entonces se hicieron famosas las albóndigas del Coronel Arrechavala" (Darío 1950: 12). Darío construye un relato de exquisito sabor local, muy gracioso y colorido, demostrándonos así un profundo conocimiento de las raíces populares de su país.

"Mis primeros versos" es el último cuento conocido que Darío escribió en Nicaragua, antes de su viaje a Chile. Aunque pretende tratarse de un relato de tipo autobiográfico, aclara Raimundo Lida que el único dato verídico de la narración aparece en la primera oración: "Tenía catorce años y estudiaba humanidades". Dice el crítico argentino, refiriéndose a este dato: 
Único detalle de realidad que aparece en este cuento; resultan muy improbables los demás que Darío refiere [...] Muchos años después Darío recordaba esta época de su juventud, cuando estudiaba con los jesuitas: "Por lo menos conocíamos nuestros clásicos y cogíamos al pasar una que otra espiga de latín y aun de griego" (Darío 1950: 13).

Este cuento trata sobre unos supuestos primeros versos rubendarianos publicados en el periódico La Calavera, como consecuencia de un temprano desengaño amoroso. Independientemente de la veracidad de esta narración, el lector puede apreciar un enternecedor orgullo de poeta que debe ser totalmente verídico: "Cuando vi, en una cuartilla de papel, aquellos rengloncitos cortos tan simpáticos; [...] se apoderó de mí una sensación deliciosa de vanidad y orgullo" (Darío 1950: 13). Sin embargo, al orgullo siguió una amarga decepción producto de aquellos, que fueron todos, los que consideraron horribles dichos versos: "Me pegaré un tiro, pensaba, me ahorcaré, tomaré un veneno, me arrojaré desde un campanario a la calle [...] porque no hay fuerzas humanas para resistir tanto" (Darío 1950: 16). Resulta cómico y a la vez triste que, tras interrogar a sus amigos, a sus conocidos, a casi toda la ciudad y hasta al editor del periódico (todos parecen ser críticos literarios), se lleva el segundo desengaño, esta vez no amoroso sino literario, quien sería el gran poeta de Hispanoamérica.

"La novela de uno de tantos" es un cuento que, aunque no se desarrolla en Nicaragua, trata acerca de las terribles desgracias que le ocurrieren a un joven nicaragüense de noble estirpe, quien acude a rogar ayuda a un paisano suyo en Guatemala, a donde su padre lo había enviado a estudiar: "[...] O te rompo el alma a palos o te vas al país vecino, donde hay universidad, a hacerte una profesión" (Darío 1950: 149). El cuento está narrado en primera persona y comienza con el encuentro del narrador-protagonista y un hombre en un estado lamentable, casi un vagabundo, quien se acerca tímidamente a suplicarle ayuda de cualquier tipo, aduciendo que, "[...] éramos del mismo lugar, que había nacido en mi tierra caliente: que tenía un libro de versos míos" (Darío 1950: 147-8). Entonces, el narrador, tras un gran esfuerzo debido a las terribles condiciones en que se encuentra aquel anciano de veintiocho años, lo reconoce como un compañero suyo del colegio, un muchacho rico y engreído, hijo del vicecónsul francés. El joven le cuenta cómo en sus años mozos dilapidó la fortuna de su padre en fiestas y con mujeres, y sin llegar a terminar una carrera universitaria. Además, le relata cómo sus padres quedaron en la ruina y lo enviaron a estudiar a Guatemala, donde volvió a las andadas, sin imaginar que al poco tiempo adquiriría una terrible enfermedad y sería aborrecido por aquellos que antes fueron sus amigos de fiestas: "Vicioso, humillado, una mañana, tras varias noches de placer abyecto, sentí un dolorcito en la garganta; y luego, señor, y luego vino esta espantosa enfermedad que me taladró los huesos y me emponzoñó la sangre" (Darío 1950: 14950). El narrador se siente muy conmovido con la historia y decide escribirla como una moraleja para los jóvenes, tanto ricos como pobres, para que tengan cuidado de no caer en dicha situación: "Lee estos renglones si eres rico, y si pobre y estudiante, y 
esperanza de tus padres, léelos dos veces y ponte a pensar en el enigma de la esfinge implacable" (Darío 1950: 150).

Se puede pensar que tal vez sintió cierta identificación, especialmente cuando aduce que, "He tenido entre mis triunfales días de oro, algunas horas negras..." (Darío 1950: 147). A pesar de que la lección de este cuento va dirigida a todos los jóvenes, parece que al seleccionar un personaje nicaragüense, es posible que el autor haya pasado su mirada crítica y alertadora, con especial énfasis, en algunos jóvenes burgueses, despreocupados e indolentes, de su país ${ }^{1}$. Por otro lado, podría ser que el cuento tenga una base autobiográfica como muchos de los de Darío.

Otro cuento rubendariano que hace una referencia, aunque más bien breve, al país de Nicaragua es la "Historia de un sobretodo". En este cuento, aparentemente autobiográfico, el narrador relata la adquisición de un sobretodo en un almacén en Valparaíso, a insistencia de un buen amigo chileno, quien le recomendó que no debía pasar ese crudo invierno sin un buen abrigo con que cubrirse. Tras la descripción de la compra del artículo, el narrador nos relata las aventuras de dicho sobretodo, ya que lo acompañó fielmente en muchos de sus viajes por diferentes países: Guatemala, Chile, El Salvador y Nicaragua, donde, por cierto, su participación fue bastante deslucida: "El estuvo en Nicaragua; pero de ese país no hubiera escrito nada, porque no quiso conocerle, y pasó allá el tiempo, nostálgico, viviendo de sus recuerdos, encerrado en su baúl" (Darío 1950: 167). Sin duda, el hermoso país tropical no tenía nada que ofrecerle al sobretodo aventurero.

Por otra parte, en El nicaragüense, Cuadra señala otra característica de sus paisanos y es que estos son muy aficionados a toda clase de historias de aparecidos y a los fenómenos de carácter sobrenatural. Muchos críticos concuerdan en que, en efecto, como Rubén Darío admite en su Autobiografia y, como se manifiesta tanto en sus poemas como en sus cuentos, siempre fue una persona muy nerviosa y profundamente impresionable ante este tipo de fenómenos. Desde su niñez, en la casa de su tía abuela Bernarda, había sufrido momentos terribles a causa no solo de la vieja casa en sí, sino también de las historias que le contaban, las que lo marcaron para siempre:

La casa era para mí temerosa por las noches. Anidaban lechuzas en los aleros. Me contaban cuentos de ánimas en pena y aparecidos, los dos únicos sobrevivientes la Serapia y el indio Goyo. Vivía aún la madre de mi tía abuela, una anciana, toda blanca por los años, y atacada de un temblor continuo. Ella también me infundía miedo, me hablaba de un fraile sin cabeza, de una mano peluda, que perseguía, como una araña [...] De allí mi horror a las tinieblas nocturnas, y el tormento de ciertas pesadillas inenarrables (Darío 1968: 19).

${ }^{1}$ Cabe pensar en escritores nicaragüenses como Ernesto Cardenal, quien confiesa en su autobiografía, Vida perdida, que vivió una juventud bastante disoluta, cosa que no era extraña entre los de su clase social. 
En su cuento "La larva", el escritor elabora en forma de cuento otro tema de carácter autobiográfico, se trata de una experiencia sobrenatural que vivió en Nicaragua: "En Caras y caretas ha aparecido una página mía, en que narro cómo en la plaza de la catedral de León, en Nicaragua, una madrugada vi y toqué una larva, una horrible materialización sepulcral, estando en mi sano y completo juicio" (Darío 1912: 127). Interesantemente, en este cuento, Darío expone ante los ojos del lector esta faceta de la cultura de su país (aunque no menciona su nombre), atribuyéndole un origen anterior a la llegada de los conquistadores españoles:

Yo nací en un país en donde, como en casi toda América, se practicaba la hechicería y los brujos se comunicaban con lo invisible. Lo misterioso no desapareció con la llegada de los conquistadores. Antes bien en la colonia aumentó, con el catolicismo, el uso de evocar las fuerzas extrañas, el demonismo, el mal de ojo (Darío 1950: 292).

Más adelante, describe algunas de las historias de aparecidos que circulaban por la ciudad en que vivió durante su niñez: la aparición del espectro de un coronel peninsular ante un joven para revelarle la localización de un tesoro (se trata evidentemente del antes mencionado Coronel Arrechavala); la aparición de un obispo ante otro joven para mostrarle donde se encontraba cierto documento perdido en los archivos de la catedral; el rapto de una mujer por el diablo; la existencia de un fraile sin cabeza, entre otros. Resulta evidente, a lo largo de la lectura, que el poeta continuaba muy impresionado por todos estos fenómenos, aunque manifiesta que solo los conoció de oídas, hasta que a los quince años tuvo una experiencia fuera de lo normal: "Pero lo que yo vi, lo que yo palpé, fue a los quince años; lo que yo vi y palpé del mundo de las sombras y de los arcanos tenebrosos" (Darío 1950: 292). Aquella terrible visión ocurrió en una ocasión en que se escapó una noche de su casa para participar en una serenata. Sentada cerca de la plaza de la Catedral, vio a una mujer y decidió acercársele para enamorarla, cuando de repente al inclinarse a mirar su rostro quedó presa de espanto: "Y cuando ya creía lograda la victoria, aquella figura se volvió hacia mí, descubrió su cara, y ¡oh espanto de los espantos! aquella cara estaba viscosa y deshecha; un ojo colgaba sobre la mejilla huesosa y saniosa; llegó a mí como un relente de putrefacción" (Darío 1950: 294). De pronto, la figura hizo una mueca macabra y produjo un ruido horrible que aterrorizó al indiscreto galán, quien "con el cabello erizado", corrió y llamó a sus compañeros, quienes no vieron nada.

Resulta muy revelador que, además de describir la terrible experiencia que vivió, incluso antes de narrarla, el escritor hable acerca de algunas tradiciones que le llamaban poderosamente la atención durante aquellos años mozos, en especial las serenatas. Por otra parte, revela algo sobre su vida en casa de su tía abuela Bernarda y las costumbres familiares como las visitas a jugar tute o hablar de política durante las noches, el rezo del rosario o las oraciones antes de dormir, y cómo su tía revisaba y cerraba con llave cada habitación antes de acostarse. En este punto de la narración, Darío no puede evitar que surjan algunos reproches del fondo del alma: "He dicho 
que tenía quince años, era en el trópico, en mí despertaban imperiosas todas las ansias de la adolescencia... Y en la prisión de mi casa, de donde no salía sino para ir al colegio, y con aquella vigilancia, y con aquellas costumbres primitivas [...]" (Darío 1950: 293). Es obvio que ya deseaba tener grandes aventuras y recorrer el mundo.

Finalmente, resulta pertinente hacer referencia a tres cuentos rubendarianos que se encuentran muy relacionados con el capítulo V de su Autobiografía, estos son "Palomas blancas, garzas morenas" (Azul 1888), "El humo de la pipa" y "Mi tía Rosa". Cuando pensamos en los cuentos de Darío que puedan relacionarse con su país de origen, enseguida viene a la mente el primero de ellos, y es que el propio autor así lo admite: "En Palomas blancas y garzas morenas el tema es autobiográfico y el escenario la tierra centroamericana en que me tocó nacer" (Darío 1912: 54). En su Autobiografia, aparece un corto párrafo que ilumina grandemente los pasajes de su cuento relacionados con aquella "paloma blanca": "A tal sazón llegó a vivir con nosotros y a criarse junto conmigo, una lejana prima, rubia, bastante bella, de que he hablado en mi cuento Palomas blancas y garzas morenas. Ella fue quien despertara en mí los primeros deseos sensuales" (Darío 1968: 23-4). Sin embargo, en este párrafo, el poeta admite que la relación amorosa que describe en el cuento no es cierta, pero que ojalá lo hubiera sido, tal como se lo hizo saber a ella muchos años después, cuando le reclamó que hubiera inventado un romance que nunca existió.

Aparte de ser un cuento de carácter autobiográfico por tratarse de su primer amor ${ }^{2}$, Nicaragua se encuentra presente como el escenario físico y emocional de los acontecimientos, infundiéndole a la narración un aliento poético ineludible. El enamorado asocia a su prima Inés, su primer amor de adolescente, con una noche tropical nicaragüense: "Y estábamos solos, a luz de una luna argentina, dulce, juna bella luna de aquellas del país del Nicaragua! [...] La pálida claridad nos iluminaba. El ambiente nos llevaba perfumes tibios que a mí se me imaginaban propicios para los fogosos amores" (Darío 1950: 88). Sin haber estado presente, el lector puede fácilmente representar en su imaginación la impactante escena: la exuberancia del paisaje tropical, que rodeaba a la pareja de jóvenes llenos de vida y, especialmente a Inés, quien rivalizaba en belleza con su entorno y se confundía con él, ante los ojos de su enamorado: "¡Cabellos áureos, ojos paradisíacos, labios encendidos y entreabiertos!" (Darío 1950: 88). Como el paisaje nicaragüense no posee solo una faceta, así Inés es también día soleado, claro y resplandeciente, lleno de aves y flores, especialmente de palomas, sus aves emblemáticas: "Un día, a pleno sol, Inés estaba en el jardín regando trigo, entre los arbustos y las flores, a las que llamaba sus amigas: unas palomas albas, arrulladoras, con sus buches níveos y amorosamente musicales" (Darío 1950: 89).

Por otra parte, tras este juvenil desengaño amoroso, renació la esperanza con la llegada de la graciosa y alegre Elena, de quien dice el poeta en su Autobiografia: "Era una adolescente de ojos verdes, de cabello castaño, de tez levemente acanelada, con esa suave palidez que tienen las mujeres de Oriente y de los trópicos" (Darío 1968:

${ }^{2}$ En este cuento, también, se manifiesta la dualidad de Darío en el aspecto amoroso. 
39). Si Inés, la de los cabellos dorados, se asociaba a las exuberantes noches tropicales y a los soleados días nicaragüenses, Elena, por su parte, se representa ante los ojos del lector del cuento como estrechamente ligada al lago nicaragüense y a su paisaje circundante en el momento del crepúsculo: "Era allá, en una ciudad que está a la orilla de un lago de mi tierra, un lago encantador, lleno de islas floridas con pájaros de colores. [...] Yo extasiado veía a la mujer tierna y ardiente; con su cabellera castaña que acariciaba con mis manos, su rostro color de canela y rosa..." (Darío 1950: 90). Los recuerdos del poeta enamorado se remontan a las hermosas tardes del trópico cuando sentado junto a su amada contemplaba la belleza del lago, descrito con impactantes imágenes plásticas: "En el cielo opalino se veía una diafanidad apacible que disminuía hasta cambiarse en tonos de violeta oscuro, por la parte del oriente, y aumentaba convirtiéndose en oro sonrosado en el horizonte profundo, donde vibraban oblicuos, rojos y desfallecientes los últimos rayos solares" (Darío 1950: 90).

Como la blancura y la pureza de las palomas hacían pensar al enamorado en su amada Inés, las garzas morenas se le asemejaban a la radiante Elena: "Mi Elena se me antojaba como semejante a ellas, con su color de canela y de rosa, gallarda y gentil" (Darío 1950: 91). El tópico de esta bella joven asociada al lago se repite en otro cuento de Darío, "El humo de la pipa", que trata acerca de una serie de alucinaciones que tiene el protagonista tras fumar una pipa, que un amigo tenía colgada en la pared de su gabinete. Entre estas visiones alucinantes, aparece una típica escena nicaragüense: el joven fumador boga por el lago junto a una bella mujer, quien por su descripción no es otra que la "garza morena", Elena: "En una barca nueva iba yo bogando camino de una de las islas, y una mujer morena, cerca, muy cerca de mí. Y en sus ojos todas las promesas, y en sus labios todos los ardores, y en su boca todas las mieles" (Darío 1950: 118). El lector se topa con una hermosa escena romántica en un ambiente paradisiaco, donde todos los elementos del paisaje se unen al regocijo de los enamorados: "Yo cortaba flores rústicas a la mujer morena, y con el ardor de las caricias las flores se marchitaban presto, diciendo también ellas: "iQué felicidad!" (Darío 1950: 118). En párrafos anteriores, se comentó que Jaime Torres aducía que el paisaje nicaragüense era el gran ausente en las descripciones de estos cuentos para cederle el paso al paisaje mediterráneo. Sin embargo, una sola lectura de estos dos cuentos es suficiente para demostrar que lejos de estar ausente, el paisaje de su amado país tropical es el gran protagonista de estas narraciones, descritas con bellas imágenes plásticas en armoniosa prosa poética.

El último cuento de esta "trilogía" amorosa, que posee estrechos vínculos con Nicaragua debido a su corte autobiográfico es "Mi tía Rosa". Esta narración breve trata acerca de un joven poeta llamado Roberto, un alter ego del propio Darío en su adolescencia, que tiene firmes intenciones de casarse con su vecina ${ }^{3}$. Cuando sus

\footnotetext{
${ }^{3}$ El protagonista oscila entre llamar a su amada vecina o prima, dato muy revelador, pues dice que esta chica es "la rubia a quien un día había sorprendido en el baño" (332), mientras que en sus memorias cuenta que en una ocasión vio a una prima suya "por sorpresa, en un aposento a donde yo entrara descuidado, me dio la ilusión de una Anadiómena" (24).
} 
padres se enteraron, armaron tremendo escándalo y decidieron enviarlo al campo, a trabajar en una hacienda para que aprendiera a ser hombre y a tomar responsabilidad por sus actos. Su tía Rosa, una agradable solterona, que bien pudo haber sido inspirada por algunos rasgos de la personalidad de su tía Josefa (Darío 1968: 24), le prometió que lo ayudaría a mantener viva su relación amorosa hasta que él regresara del campo. Sin embargo, como se relata en el cuento, el destino se encargó de tronchar estos planes: "En una mula bien aperada, y en compañía de un negro mayordomo, partí a la hacienda. Allá escribí más poesías que nunca, y tiempo después me alejaba muy lejos. A mi vecina no la volví a ver sino ya viuda y llena de hijos. Y a mi tía Rosa no la volví a ver jamás, porque se fue al otro mundo con sus azahares secos" (Darío 1950: 335). Sin duda, este cuento estuvo inspirado en la propia adolescencia nicaragüense del poeta, ya que en sus memorias comenta que, "Un día dije a mis amigos:-Me caso. [...] Como mis buenos querendones viesen una resolución definitiva en mi voluntad, me juntaron unos cuantos pesos, me arreglaron un baúl y me condujeron al puerto de Corinto, donde estaba anclado un vapor que me llevó en seguida a la república de El Salvador" (Darío 1968: 41).

Los posibles vínculos de Nicaragua con estos cuentos rubendarianos pueden ser más o menos fuertes y más o menos evidentes, ya que en algunos se limita a un fino hilo conector por tratarse de narraciones autobiográficas. Sin embargo, aún estos últimos demuestran la estrechez de los lazos que el poeta mantuvo con su patria y los recuerdos que atesoró hasta el final de sus días. Algunos rasgos típicamente nicaragüenses como el hermoso paisaje tropical y las tradiciones populares se encuentran magnífica y amorosamente delineados no sólo como telón de fondo para situar la narración, sino como esencia viva y, a veces, hasta protagónica en estos cuentos. En el prólogo de su Autobiografía, Gustavo García Saraví no pudo haberse expresado mejor, al decir del poeta: "Nicaragüense, a secas, que basta y sobra la alusión del adjetivo con geografías, igual que en la designación del Greco o el Estagirita. Centroamérica, con él, se transforma en un mapa con estrofas y maravillas" (Darío 1968: 7).

\section{BIBLIOGRAFÍA}

ANDERSON IMBERT, Enrique.

1967 La originalidad de Rubén Darío. Buenos Aires: Centro Editor América Latina.

ARELLANO, Jorge Eduardo.

1977 Panorama de la literatura nicaragüense. Managua: Ediciones Nacionales.

CARDENAL, Ernesto.

1949 "Ensayo preliminar", en Antología de la poesía nicaragüense. Madrid: Cultura Hispánica.

1999 Vida perdida. Barcelona: Seix Barral. 
CORONEL URTECHO, José.

1966 "Introducción al tema de la universalidad nicaragüense", Revista Conservadora del Pensamiento Centroamericano, vol. 22, $\mathrm{n}^{\mathrm{o}}$ 69, 1966:2-7.

CUADRA, Pablo Antonio.

1969 El nicaragüense. Madrid: Ediciones Cultura Hispánica.

DARÍO, Rubén.

1912 Historia de mis libros. Buenos Aires.

1950 Cuentos completos. Ed. de Ernesto Mejía Sánchez. México-Buenos Aires: Fondo de Cultura Económica.

1968 Autobiografia. Buenos Aires: Editorial Universitaria.

LOVELUCK, Juan (ed.)

1967 Diez estudios sobre Rubén Darío. Santiago de Chile: Empresa Editorial Zig-Zag.

MARRERO, Vicente.

1970 Nuestro Rubén. Madrid: Ediciones Cultura Hispánica.

MARTín, Carlos.

1972 América en Rubén Darío. Madrid: Gredos.

SEQUEIRA, Diego Manuel.

1945 Rubén Dario, criollo; o, raiz y médula de su creación poética. Buenos Aires: Guillermo Kraft.

TORRES BODET, Jaime.

1966 Rubén Darío. México: Fondo de Cultura Económica.

YCAZA TIGERINO, Julio.

1967 Estudio de la poética de Rubén Dario. Managua, Comisión Nacional del Centenario. 